\title{
POLÍTICAS IMIGRATÓRIAS: O NACIONAL E O UNIVERSAL
}

\author{
Immigration Policies: the national and the universal scopes
}

\begin{abstract}
Ademir Alves da Silva ${ }^{1}$
\section{Resumo}

O presente texto apresenta o resultado de estudo preliminar sobre a questão das imigrações no contexto da crise capitalista contemporânea, a partir de matérias selecionadas de periódicos. São identificadas, nas pautas de movimentos e partidos ultraconservadores, variadas expressões de xenofobia, hostilidade e intolerância em relação aos imigrantes em vários países, evidenciando a contradição entre a desregulação e livre circulação de capitais e mercadorias e, por outro lado, as crescentes restrições ao deslocamento de pessoas. O estudo permitiu entrever nas atitudes de rejeição aos imigrantes as armadilhas ideológicas da conversão do diferente em inimigo recobrindo interesses econômicos na exploração de mão de obra - sob o pretexto de incompatibilidades étnico-culturais supostamente ameaçadoras de "integridades nacionais". Foi possível, portanto, identificar a tendência de transmutação da oposição entre trabalhadores nacionais e trabalhadores imigrantes - que serve aos interesses de redução dos custos de mão de obra -, em questões de preservação da ordem, segurança e identidade cultural. As reflexões permitiram reiterar, ao final, a importância de políticas públicas que, mediante mecanismos democráticos de regulação, assegurem a inserção e a participação dos trabalhadores imigrantes na vida social, cultural, política e econômica do país de destino, segundo princípios de convenções e tratados internacionais e sob critérios universalistas de justiça social.
\end{abstract}

Palavras-chave: Imigrantes. Direitos humanos. Políticas imigratórias. Relações internacionais.

\begin{abstract}
This text presents the results of a study about the immigration issue in the context of the contemporary capitalist crisis, based in selected newspaper articles. Several expressions of xenophobia, hostility and intolerance against the immigrants are identified in many countries, on the agenda of the ultra conservative movements and parties. This reveals the contradiction between, on the one hand, the deregulation and free circulation of capitals and goods and, on the other hand, the growing restrictions to the displacement of people. The study suggests that the rejection attitudes against immigrants are, in fact, ideological traps that convert the different ones in enemies. This fact recovers economic interests of exploiting labor force, under de pretext of ethnic and cultural incompatibilities, allegedly threatening the national integrity. It was possible, therefore, to identify the trend towards transmuting the opposition between national workers and immigrant workers - which serves to the labor cost reduction interests- in issues of order, security and cultural identity preservation. Reflections allowed to reinforce, at the end, the importance of public policies that, by democratic means of regulation, ensure the insertion and the participation of the immigrant workers in the social, cultural, political and economical spheres of the destination country, according to principles of the international conventions, under universal criteria of social justice.
\end{abstract}

Key words: Immigrants. Human rights. Immigration policies. International relations.

\footnotetext{
${ }^{1}$ Docente, pesquisador e Coordenador do Programa de Estudos Pós-Graduados em Serviço Social da Pontifícia Universidade Católica de São Paulo. Telefone 11 98331-7427, e-mail: adecris@uol.com.br.
}

Serv. Soc. \& Saúde, Campinas, SP v. 13, n. 2 (18) p. 261-282 jul./dez. 2014 ISSN 1676-6806 


\section{INTRODUÇÃO}

A chegada do circo era pura alegria. A criançada saltava aos gritinhos: $O$ circo chegou. Amanhã é domingo. Vamos ao circo!

Itinerante, a companhia circense deslocava-se de uma cidade para outra sob a chamada "Não percam", anunciando sua programação com a garantia de grandes emoções para todas as idades ${ }^{2}$. A trupe nômade constituía-se de pessoas de diversas origens e nacionalidades, sob a direção de uma ou mais famílias estrangeiras.

Aquela geração foi fortemente influenciada pelos padres salesianos, especialmente os italianos, mas havia também o tcheco, o alemão e o polonês, com os diferentes sotaques na leitura dominical do texto do evangelho - Naquele tempo, Jesus... -, seguida pela homilia. O legado da cultura religiosa católica, por meio daquele sacerdócio estrangeiro, forjou o nosso cotidiano num contexto de relações internacionais intermediadas pela Igreja, a primeira organização supranacional a exercer a mais visível e inequívoca influência em nosso cotidiano, seguida pelos produtos da Nestlé e pelas notícias do repórter Esso, outras duas multinacionais.

Os sacerdotes e religiosos católicos seguiram influenciando sucessivas gerações. Mas aquele circo de nossa infância já não existe ${ }^{3}$. Atualmente, o Cirque du Soleil, companhia canadense, pela combinação de várias artes do espetáculo ${ }^{4}$, segue respondendo ao apelo de que "o show deve continuar", valendo-se do trabalho equivale dizer, do corpo - de inúmeros homens e mulheres expatriados. Situação similar ocorre com a tripulação de navios, constituída de trabalhadores de diversas nacionalidades, a serviço dos animados cruzeiros entre mares ${ }^{5}$.

Naquela pequena cidade, para as crianças daquela geração, os artistas circenses, os sacerdotes católicos e os ciganos, dentre outros expatriados ou "estrangeiros",

\footnotetext{
${ }^{2} \mathrm{~A}$ instalação do itinerante parque de diversões também era acontecimento que agitava a cidade. Em outro contexto, o filme Jour de Fête (Dia de Festa) ou Carrossel de Esperança, de Jacques Tati, França, 1949, retrata com rara sensibilidade e beleza o impacto da chegada do carrossel ao vilarejo.

${ }^{3}$ No Brasil, encontram-se em atividade, sob novas condições e diversas modalidades, o Vostok, o Tihany e o Marcos Frota Circo Show, dentre outros.

${ }^{4}$ Exemplo dessa combinação é a peça Ta Fantastika - Aspects of Alice, baseada em Lewis Carrol, ora exibida no Black Light Theatre de Praga, que combina performance de atores e palhaço com animações, marionetes, efeitos especiais e truques, desenho animado, acrobacia, música clássica e contemporânea, luz, som e imagem.

${ }^{5}$ Os filipinos constituem um quinto dos marujos do mundo e $25 \%$ da mão de obra filipina está no exterior (DEPARLE, 07/06/10).

Serv. Soc. \& Saúde, Campinas, SP v. 13, n. 2 (18) p. 261-282 jul./dez. 2014 ISSN 1676-6806
} 
indicavam a grandeza do mundo e a extensão da humanidade, para muito além daquele microuniverso "local".

Para aquela geração, a chegada dos ciganos despertava curiosidade e encantamento. Alegres, festivos, ruidosos, coloridos, os ciganos subvertiam a rotina local. Mas, ao contrário do grande toldo do circo, as tendas dos ciganos suscitavam sentimentos auto defensivos e de intolerância, que os adultos transmitiam às crianças. Eram indisfarçáveis o preconceito e a xenofobia em face daqueles grupos nômades.

Perseguidos na Alemanha nazista, hoje os $\operatorname{ciganos}^{6}$ seguem sendo vítimas da aversão dos nacionais como ocorre na França ${ }^{7}$, que vem desmantelando acampamentos e repatriando ciganos romenos e búlgaros ${ }^{8}$ sob a justificativa oficial de que "os ciganos não têm emprego, não pagam impostos, oneram os sistemas públicos de saúde e educação e aumentam a violência nas cidades” (MARINHEIRO: 15/09/10).

Na Hungria ${ }^{9}$,

[...] o preconceito contra os rom - conhecidos amplamente como ciganos e que há muito tempo estão entre os grupos minoritários mais oprimidos da Europa - vem aumentando e assumindo a forma de uma onda de violência [...] um ambiente cada vez mais agressivo em relação aos ciganos na Hungria e em outras partes da Europa central e oriental, onde partidos de extrema direita cujos líderes jogam com os velhos estereótipos dos rom como pequenos criminosos e do ônus que supostamente impõem aos sistemas de bem-estar social, num período de turbulência econômica e política crescente (KULISH, 04/05/2009, destaques meus).

Por violar as leis sobre a livre circulação de pessoas pelos países membros da União Europeia, a política de expulsão é objeto de denúncia por organismos supranacionais como a Comissão Europeia - corpo executivo da União Europeia - e o Comitê para a Eliminação da Discriminação Racial da ONU.

Na Europa recrudescem as atitudes de intolerância, hostilidade e xenofobia. Expressões dessa tendência são o partido do Front National da França; a Lega Nord da Itália; a proibição da construção de minaretes islâmicos na Suíça; o controle, na

\footnotetext{
${ }^{6} \mathrm{Na}$ Europa são 9,1 milhões de pessoas com maior concentração na Romênia, seguida pela Bulgária, Espanha, Sérvia, Eslováquia, Hungria, Turquia, França e outros países. (Cf. Os ciganos na Europa. Folha de S. Paulo, 20/8/10, apud Liégeois, Jean-Pierre. Os ciganos na Europa. 2007).

7 Imache (2008) aborda a "violência da deportação" e as ações dos centros franceses de detenção administrativa contra estrangeiros.

${ }^{8}$ Cerca de 10 mil deixaram o país em 2009 (CARDOSO, 2010).

${ }^{9}$ O filme Apenas o vento (Csak a Szél) de Benedek Fliegauf, Hungria, 2012, retrata a perseguição a ciganos na Hungria no contexto da crise pós-2008.

Serv. Soc. \& Saúde, Campinas, SP v. 13, n. 2 (18) p. 261-282 jul./dez. 2014 ISSN 1676-6806
} 
Dinamarca, das fronteiras com a Alemanha e a Suécia, sob o argumento do aumento da violência e da criminalidade praticados por imigrantes, além dos alegados custos de manutenção de imigrantes da Somália e do Paquistão; as restrições, na Inglaterra, à contratação de estrangeiros e à concessão de vistos para estudantes, tendo como alvo os trabalhadores menos qualificados do leste europeu e asiáticos, os muçulmanos e os afegãos refugiados de guerra; a oferta de até US\$ 3 mil para estrangeiros deixarem o Japão que, anteriormente, havia incentivado a imigração para enfrentar a falta de mão de obra (DONADIO et al, 2009; DEPARLE, 2010); as manifestações da extrema-direita na Holanda, Hungria e Suécia ${ }^{10}$.

Um representante da Lega Nord italiana assim se manifesta sobre os imigrantes:

ROMA, 5 OTT 2012 - "'Somos contra uma Europa multiétnica, resultante da ilimitada e contínua imigração, que está pondo em risco a cultura, a história e as raízes dos povos europeus. Não podemos nos curvar em face desse fenômeno, que deve ser combatido em todas as instâncias adequadas para preservar as tradições dos nossos povos". É o que disse o deputado da Liga Norte, Claudio D'Amico, durante a sessão de outono da Assembleia Parlamentar da OSCE [...]. "Não há dúvida de que a maioria dos imigrantes que chegaram nos últimos vinte anos à Europa, e em particular os muçulmanos e chineses, não tem nenhuma intenção de integrar-se e de aceitar os nossos valores e nossa cultura, mas ao contrário visam substituir as nossas tradições. $\mathrm{O}$ risco é que, se não revertermos essa tendência de imediato, isto logo conseguirão, uma vez destinados a se tornarem maioria"11 (Original em italiano. Tradução de minha responsabilidade)

E o segmento de jovens representados na UDC/SVP - União Democrática de Centro/Partido do Povo da Suíça declara, a propósito dos imigrantes:

Nossas regras são válidas para todos! Os problemas relacionados com a política de asilo e estrangeiros devem poder ser abertamente debatidos e tematizados [...] Os jovens da UDC reivindicam que critérios claros e rigorosos para a naturalização sejam aplicados e mantidos. Para os jovens da UDC, não há direito de recurso em matéria de naturalização. Os pedidos de naturalização devem ser tratados de maneira restritiva. Ser cidadão suíço deve voltar a ser uma honra e um privilégio e a concessão do passaporte cruz branca não deve ser considerada um assunto administrativo comum. $\mathrm{O}$ direito à cidadania suíça é o resultado de uma integração bem sucedida. [...] A tendência de naturalização em massa aumentou. [...]. O número de naturalizados anualmente aumentou nove vezes desde 1990! Esta tendência deve ser interrompida imediatamente. [...] A proporção de estrangeiros na Suíça está crescendo continuamente. [...] Os números

\footnotetext{
${ }^{10}$ Em meu curso de Inglês a professora (native teacher) dizia, sobre a aversão aos imigrantes em seu país, a Inglaterra, e na Europa em geral: "Fizemos o banquete (na colonização), agora estamos recusando a sobremesa"

${ }^{11}$ Osce: D’Amico, contrari a Europa multietnica. Disponível em: www.leganord.org/index.php/notizie. Acesso em: 18/11/12.
}

Serv. Soc. \& Saúde, Campinas, SP v. 13, n. 2 (18) p. 261-282 jul./dez. 2014 ISSN 1676-6806 
estão aumentando, em 2009, a Suíça teve uma proporção alarmante de 23\% de estrangeiros. [...] A naturalização está sujeita a um período experimental e pode ser revogada durante este período, por exemplo, no caso de uma condenação penal. [...] Os criminosos devem ser deportados e [...] impedidos de entrar no território. As autorizações de residência devem ser canceladas em caso de crime grave, e a pessoa deve ser deportada para seu país de origem. A lei antirracismo deve ser suprimida porque restringe fortemente o direito à livre expressão de opinião do cidadão"12 (Original em francês. Tradução de minha responsabilidade).

A xenofobia e as hostilidades contra os imigrantes manifestam-se também na Grécia pelas ações do partido ultranacionalista Aurora Dourada ${ }^{13}$. Na Finlândia, as últimas eleições legislativas registraram um avanço do partido dos Verdadeiros Finlandeses $^{14}$, nacionalista e anti-imigração. Na Rússia, imigrantes procedentes da Ásia Central são retratados, em cartilha de orientações, na forma de vassouras e outros utensílios, e não como pessoas ${ }^{15}$. Os imigrantes ilegais, especialmente os oriundos de ex-repúblicas soviéticas como o Uzbequistão e o Tadjikquistão são vítimas de perseguição por grupos de jovens como os do Escudo de Moscou que "desfruta de considerável liberdade de ação, sem oposição - e ocasionalmente com assistência tácita - da polícia, enquanto seus membros adotam táticas agressivas e até mesmo ilegais" (ROTH, 24/09/13).

A polêmica em torno da tolerância ou veto ao uso de véu ${ }^{16}$ por mulheres mulçumanas, em países da Europa, é outra expressão das hostilidades a imigrantes. No norte da Itália algumas cidades aplicam multas a mulheres, com base em lei antiterror, de 1975, que proíbe cobrir o rosto em lugares públicos. Na França, o uso do véu, já proibido em escolas, é objeto de discussão no Senado. Na Bélgica, os véus são proibidos. Na Espanha, não há lei federal, mas cidades da Catalunha baniram a burca. Na Holanda, partidos de direita preconizam a proibição. Na Alemanha, a proibição seria inconstitucional. No Reino Unido, a proibição iria contrariar princípios. (MARINHEIRO, 25/07/10).

\footnotetext{
${ }^{12}$ Cf. Étrangers en Suisse. Disponível em: http://www.jsvp.ch/francais/positions. Acesso em 16/11/12.

${ }^{13}$ Cf. Grécia: ONGs dizem que imigrantes são "bodes expiatórios" para a crise. Disponível em: www.euronews. 20/10/12. Acesso em 19/11/12.

${ }^{14}$ Cf. Finlândia enfrenta subida do populismo. Disponível em: www.euronews. 06/05/11. Acesso em 19/11/12.

${ }^{15}$ Cf. Imigrantes desenhados como vassouras choca Rússia. Disponível em: www.euronews. 24/10/12. Acesso em 19/11/12.

${ }^{16}$ Os véus são de vários tipos: hijab, na Arábia Saudita; xador, no Irã; niqab, nos países árabes; e burca no Afeganistão e Paquistão (DIAS, KANNO, BAPTISTA, PULS, SEVERINO, DUCROQUET, PLIGER E CAVALEIRO: 03/03/11).

Serv. Soc. \& Saúde, Campinas, SP v. 13, n. 2 (18) p. 261-282 jul./dez. 2014 ISSN 1676-6806
} 
Trata-se, segundo tais movimentos, de combater a criminalidade e a violência, proteger-se do terrorismo, reduzir as pressões sobre o mercado de trabalho e os serviços públicos ou de preservar a identidade e a cultura nacionais: o tribalismo viking milenar, a supremacia branca americana de ascendência europeia, a civilização europeia.

O fato é que no contexto da crise, os imigrantes tendem a ser criminalizados, especialmente os segmentos considerados clandestinos, ilegais, sem visto de residência, sem-papéis ou indocumentados. Muito distantes do green card.

Expressão desse nacionalismo xenófobo, tendo como alvo oito milhões de imigrantes, foi a aprovação em 2008, pelo Parlamento Europeu, da Diretriz do Retorno, em desacordo com o Tratado de Schengen, do qual são signatários 24 países, que estabelece a livre circulação de pessoas no território da União Europeia.

Nos Estados Unidos ganha força, no contexto da crise, a xenofobia e os ataques aos imigrantes ilegais, especialmente após a promulgação da Lei SB1070 de Imigração, do Arizona, em julho de 2010. Grupos de direita preconizam abertamente a "supremacia branca". Passam a ser atacados o "turismo de parto" ou "turismo de nascimentos" ou "bebê-âncora", acusados de serem estratégia para assegurar a nacionalidade americana. Reacende a polêmica quanto à determinação de nacionalidade ${ }^{17}$, seja pelo jus soli (solo onde se nasce) ou pelo jus sanguinis (laços de sangue e ancestralidade). (MURTA, 12/08/10; SCHWARTSMAN, 12/08/10).

No entanto, em contexto de crescente hostilidade a imigrantes, o voto latino foi decisivo na reeleição de Barack Obama que já havia declarado que "os imigrantes sempre ajudaram a construir e defender este país. Ser americano não é uma questão de sangue ou nascimento. É questão de fé" (FIBE, 02/07/12). Agora, ganha força o projeto de reforma imigratória em favor de estrangeiros que vivem ilegalmente nos EUA, estimados em 11 milhões de "indocumentados".

Segundo Naim (07/12/12)

[...] a despeito dos problemas do regime de imigração, os EUA seguem sendo o destino preferencial dos profissionais mais capacitados do mundo. Por fim, a população americana é mais jovem, tem mais crianças e está crescendo mais rápido, via imigração, do que a dos demais países avançados e da China.

\footnotetext{
${ }^{17}$ No Brasil, o "casamento de aluguel" ou "casamento arranjado" de estrangeiros com brasileiros e a declaração de união estável consistem em estratégias para a obtenção da permanência legal no país. (MARTIN, 08/07/12).

Serv. Soc. \& Saúde, Campinas, SP v. 13, n. 2 (18) p. 261-282 jul./dez. 2014 ISSN 1676-6806
} 
A criminalização e a perseguição aos imigrantes servem a interesses políticos como foi o caso da reeleição de Silvio Berlusconi na Itália e da reeleição do governador de Hessen, Roland Koch, do partido conservador alemão, sob o slogan Kinder statt inder (Crianças em vez de indianos) ${ }^{18}$. Foi também o caso de Nicolas Sarkozy, na tentativa mal sucedida de reverter a tendência de perda de popularidade junto ao eleitorado francês.

Ora, na luta pela sobrevivência animais em geral migram. Os seres humanos sempre migraram. A história da humanidade é marcada pelos deslocamentos - a jornada, a travessia, a viagem, a saga, a aventura, a fuga.

[...] a 'pureza' italiana, que se trata de preservar, é o fruto de uma incrível mistura: as invasões bárbaras, a dos normandos na Sicília, o domínio austríaco no Norte do país e espanhol no Sul, etc. (CALLIGARIS, 24/07/2008).

Autonomia não significa isolamento. Identidade é expressão de um processo histórico marcado por integração, conflito e cooperação, alianças, rupturas e conciliações. Intenções puristas e separatistas não podem prosperar, senão por meio da violência e da aberta violação dos direitos humanos:

Segundo a Declaração Universal dos Direitos Humanos:

Art. XIII

1. Toda pessoa tem direito à liberdade de locomoção e residência dentro das fronteiras de cada Estado.

2. Toda pessoa tem o direito de deixar qualquer país, inclusive o próprio, e a este regressar.

Art. XIV

1. Toda pessoa, vítima de perseguição, tem o direito de procurar e de gozar asilo em outros países.

2. Este direito não pode ser invocado em caso de perseguição legitimamente motivada por crimes de direito comum ou por atos contrários aos propósitos e princípios das Nações Unidas.

Art. XV

1. Toda pessoa tem direito a uma nacionalidade

2. Ninguém será arbitrariamente privado de sua nacionalidade, nem do direito de mudar de nacionalidade.

Entretanto, a globalização, que representou (des)regulação e livre circulação de capitais e de mercadorias, vem impondo crescentes restrições ao deslocamento de pessoas. O capital suplanta quaisquer fronteiras, geográficas e éticas. O capital escolhe onde, o que, como e quem explorar. Trabalhadores representam mão de obra, mão de

\footnotetext{
${ }^{18} \mathrm{Cf}$. Crossland, David. Xenofobia at the heart of German Politics. Disponível em: www.spiegel.de/international/germany Acesso em: 5/4/12. Ver também: Brito, 2008. Serv. Soc. \& Saúde, Campinas, SP v. 13, n. 2 (18) p. 261-282 jul./dez. 2014 ISSN 1676-6806
} 
obra constitui o custo variável e manipulável da produção. Os capitais são contemplados com desregulação, incentivos, socorro governamental. Os trabalhadores imigrantes são confinados nos centros de retenção administrativa ou de permanência provisória (provisoire séjour), criminalizados, perseguidos, presos, deportados. Num mundo em que as finanças subordinam a política e os governos, não há lugar para políticas de valorização e respeito à vida dos imigrantes.

O fato é que a imigração responde aos ciclos econômicos. Então, conforme a circunstância, a política imigratória pode consistir em incentivar o ingresso de estrangeiros para preencher postos de trabalho de alta - os skilled migrants - ou de baixa qualificação, explorar o trabalho de imigrantes ilegais, responsabilizar os imigrantes pela falta de empregos, coibir a contratação de imigrantes, restringir autorizações para estudantes, oferecer dinheiro para o retorno.

Quanto aos incentivos para o retorno, o Japão

[...] na década de 1990 [...] estimulou latino americanos a irem ajudar a reduzir sua escassez de mão de obra, mas agora tem pago até US\$ 3 mil para esses trabalhadores deixarem o país [...] os decasséguis rapidamente se tornaram o maior grupo de trabalhadores estrangeiros nesse país em geral avesso à imigração, preenchendo os empregos “triplo K”- kitsui, kitanai, kiken - duros, sujos e perigosos. (DONADIO, R; TABUCHi, H.; SCHUWARTZ, 04/05/09, destaques meus).

No caso de Cuba, a reforma migratória responde a exigências econômicas:

O discurso de Alarcon (presidente da Assembleia Nacional de Cuba) explicita uma intenção do regime: atrair uma migração 'não ideológica' recente, que fez dinheiro fora da ilha, especialmente em Miami, e que teria interesse em injetar capital em Cuba no momento em que o país implementa reformas econômicas (MARREIRO, 2012).

Tratou-se de flexibilizar as restrições vigentes. Para os cubanos viajarem, precisavam obter o "cartão branco" que consistia em "permissão de viagem ao exterior". Os emigrantes que desejassem retornar ao país também deveriam cumprir exigências. Em conversa com uma funcionária de escola, em julho de 2012, em Havana, ela disse ao autor deste artigo: "Não podemos sair do país. É necessário um convite. Há poucos dias, a senhora Diretora foi convidada para um Congresso fora do país. Neste caso, é possível".

Agora, com as novas medidas migratórias que entraram em vigor a partir de 14/01/13, elimina-se a exigência da permissão de saída. O tempo de permanência no exterior foi ampliado de 11 para 24 meses, podendo ser renovado. Acaba a exigência de 
visto de entrada para quem emigrou até 1971 ou após 1994, além de médicos e esportistas depois de 1990. Prazo passa a ser de três meses, prorrogáveis. Foram ampliados os casos de permissão de residência ${ }^{19}$.

Em 2011, a Alemanha e a Áustria suspenderam as restrições para imigrantes do Leste Europeu, adotadas em 2004. A Alemanha depende de trabalhadores qualificados para a área de engenharia, dentre outras, e de trabalhadores de baixa renda para as funções de cuidadores do crescente segmento de pessoas idosas (DEMPSEY, 21/02/2011).

Conforme as condições no país de origem e os atrativos do país de destino

[...] existem grupos de trabalhadores que, buscando alternativas para a fome e a pobreza, migram para outros países na esperança de encontrar trabalho: a mão de obra indiana está construindo as novas cidades de Dubai e Doha; os poloneses assumiram grande parte do trabalho na área de hotelaria e turismo na Grã-Bretanha, empregando-se em hotéis, bares e cafés; os turcos são largamente empregados nas fábricas alemãs; as empregadas filipinas são admitidas em todo o Oriente Médio e Europa (MATTEWMAN, 2012, p. 56).

Chineses também emigram, principalmente, por razões econômicas, mas também devido a fatores políticos. "Segundo o Ministério do Comércio, 800 mil cidadãos chineses estavam trabalhando fora do país no final de 2011, contra apenas 60 mil em 1990" (JOHNSON, 12/11/12).

No contexto da crise, Portugal vem procurando atrair investidores brasileiros, chineses, russos e angolanos. Espera-se dos milionários brasileiros a participação em empresas estatais privatizadas, investimento no mercado financeiro, abertura de negócio com geração de empregos, compra de imóvel de ao menos 500 mil euros. Nesse caso, o visto provisório valerá por cinco anos, podendo converter-se em residência permanente na Europa (CARNEIRO, 28/09/12). Por outro lado, cresce a emigração de profissionais portugueses para trabalhar no Brasil ${ }^{20}$.

As migrações de brasileiros radicados no Paraguai devem-se a fortes interesses econômicas. O agronegócio é fator de conflito na fronteira entre Brasil e Paraguai, opondo os brasilguaios - latifundiários brasileiros - e os carperos - trabalhadores paraguaios sem-terra acampados. Responsáveis "em grande medida" pelo crescimento econômico de $15 \%$ em 2010, os produtores rurais são, por outro lado, acusados de

\footnotetext{
${ }_{20}^{19}$ Cf. Cuba admite o retorno de cidadãos que fugiram. Folha de S. Paulo. Caderno Mundo. 26/10/12.

${ }^{2}$ Cf. a matéria Cresce presença de engenheiro português no país. Folha de S. Paulo, 28/09/12.
}

Serv. Soc. \& Saúde, Campinas, SP v. 13, n. 2 (18) p. 261-282 jul./dez. 2014 ISSN 1676-6806 
usarem sementes geneticamente alteradas e agrotóxicos, concentrando terras e expulsando trabalhadores do campo (CAPRIGLIONE, 01/02/12 e 05/02/2012).

Baixa natalidade, falta de mão de obra qualificada e crescimento econômico determinam, no caso do Canadá, uma política de incentivo à imigração. Em 2007, a então Ministra de Imigração e Comunidades Culturais da Província do Québec, dizia: "Construímos este país com a imigração. Somos um povo velho e precisamos de imigrantes para nos desenvolver". No Canadá, a política de multiculturalismo adotada em 1971 converteu-se em lei em 1988 (VILA-NOVA, 26/12/07).

O Canadá recebe, em média, 250 mil novos imigrantes por ano. Essa forte tradição migratória explica-se em parte pela política de multiculturalismo adotada pelo país desde 1971 e que se transformou em lei em 1988. Apenas em Montréal, a maior cidade da Província do Québec, convivem 125 diferentes nacionalidades - são 220 etnias em todo o país. Toronto, na Província de Ontário, é tida como a cidade mais multicultural: $20 \%$ da população é de origem estrangeira (VILANOVA, 2007, destaques meus).

Na França, imigrantes ilegais - os sans papier - decidiram, a partir de 2008, aderir a greves e manifestações públicas. Dada a situação de estrangeiros irregulares veem-se obrigados a aceitar condições de trabalho extremamente precárias, que os franceses não aceitariam: horas não remuneradas, não-pagamento de demissões e indenizações, trabalho noturno e de fim de semana (PIOT, 2008). Ocorre que, embora ilegais, tem contratos e são registrados nas empresas, recolhem impostos e contribuem com os fundos sociais. São ilegais, mas necessários em "setores como hotelaria, restaurantes, construção civil, segurança, limpeza, agricultura, ou trabalhando como empregados domésticos, cozinheiros, etc., eles têm como denominador comum o fato de serem todos assalariados" (PIOT, 2008).

Na Coréia do Sul,

[...] a maioria dos imigrantes é constituída por mulheres do Vietnã e de outros países asiáticos mais pobres. Nas cidades industriais, rapazes de Bangladesh e do Paquistão desempenham funções recusadas pelos coreanos como sujas e perigosas. Eles oferecem a mão de obra barata que a economia sul-coreana, voltada para as exportações, precisa para competir com a China. O número desses trabalhadores mais que duplicou, de 260 mil, em 2007, para 553 mil, no ano passado - sem contar os que têm visto expirado e trabalham ilegalmente. Um em cada dez casamentos na Coréia do Sul envolve um cônjuge estrangeiro (SANG-HUN, 17/12/12, destaques meus). 
No Brasil vem aumentando, no estado de São Paulo, o número de estrangeiros em busca de emprego formal e, consequentemente, o registro de trabalhadores imigrantes:

Até junho deste ano foram emitidas 5.431 carteiras de trabalho pela superintendência do Ministério do Trabalho em São Paulo. O número é $23 \%$ superior ao de igual período do ano passado, quando 4.411 estrangeiros conseguiram o documento. São os trabalhadores da América Latina os que lideram as três primeiras posições do ranking da carteira para estrangeiros neste ano: bolivianos (2.432), peruanos (303) e paraguaios (281) (ROLLI, 11/08/13).

Os bolivianos, peruanos e paraguaios são absorvidos pelo setor têxtil; os haitianos, pela construção civil; os franceses, pelo setor farmacêutico; os argentinos, espanhóis e franceses, pelo setor de turismo, bares e restaurantes; os espanhóis e franceses, pelas telecomunicações e tecnologia da informação; e os portugueses, pelo setor de varejo (ROLLI, 11/08/13).

$\mathrm{Na}$ condição de trabalhadores, em diferentes níveis de qualificação, os imigrantes constituem fator decisivo para as economias nacionais, tanto nos países de origem quanto nos países de destino. Segundo o relatório do PNUD (2009), a migração é maior entre países emergentes e o valor das remessas dos migrantes a seus países de origem é maior que o da cooperação internacional.

[...] o valor total desses envios equivaleu em 2007 a quatro vezes a ajuda oficial ao desenvolvimento, desembolsada principalmente pelos países mais ricos. Na América Latina e no Caribe, as remessas equivaleram a $60 \%$ da soma da ajuda internacional e dos investimentos diretos. ${ }^{21}$

Ainda segundo o relatório do PNUD (2009)

Ao contrário do que normalmente se acredita, os migrantes estimulam a produtividade econômica e dão mais do que aquilo que recebem. Investigações detalhadas mostram que a imigração geralmente aumenta o emprego nas comunidades que recebem os migrantes, não expulsa os nativos do seu mercado de trabalho e melhora as taxas de investimento em novos negócios e iniciativas. De uma maneira geral, o impacto dos migrantes nas finanças públicas tanto em nível nacional como local - é relativamente pequeno, e existem claras evidências que apontam para benefícios em outras áreas como a diversidade social e a capacidade de inovação (PNUD, 2009, destaques meus).

\footnotetext{
${ }^{21}$ Cf. matéria Migrantes ajudam mais que países ricos. Folha de S. Paulo, 05/10/09.

Serv. Soc. \& Saúde, Campinas, SP v. 13, n. 2 (18) p. 261-282 jul./dez. 2014 ISSN 1676-6806
} 
$\mathrm{Na}$ Europa e nos EUA, as posturas auto defensivas levam a tendências nostálgicas de resgatar o nacional, o comunitário, o tribal, sob a alegação de preservação de uma particular e inconfundível identidade.

Porém, vale indagar: Qual é a nacionalidade do capital e dos capitalistas? Ora, no contexto da internacionalização da economia, empresas e capitalistas se desterritorializam, desenhando nova geografia econômica, em busca de incentivos fiscais, mão de obra barata e débil organização sindical. O capital financeiro especulativo desloca-se on line em direção às maiores taxas de rentabilidade. Existe nação para o capital? O que existe são relações econômicas, sociais e políticas. Relações de poder entre classes e camadas sociais, que suplantam fronteiras nacionais. Capitais e mercadorias sem fronteiras, pessoas impedidas de migrar.

Ora, trata-se de afirmar, para as pessoas, a esfera do universal. Referências identitárias ou nacionais não podem suplantar a conquista da paz e da justiça social. Como reconhecer e respeitar diferenças étnico-culturais sem combater desigualdades? O chamado multiculturalismo mascara e reproduz relações desiguais.

[...] o multiculturalismo fracassou por não ser suficientemente multicultural. Ele nunca conseguiu realmente integrar imigrantes como sujeitos políticos, partilhar poder e compreender que a verdadeira multiplicidade não é a soma de identidades isoladas onde um 'tolera' o outro. A verdadeira multiplicidade é o movimento de dissolução das identidades em direção à construção de universalidades realmente inclusivas (SAFATLE, 2011).

A Convenção das Nações Unidas para a proteção de todos os trabalhadores migrantes e membros de suas famílias (1990) estabelece os direitos do imigrante de sair e regressar; de liberdade de pensamento, consciência, religião e expressão; de ter assistência de autoridades diplomáticas e consulares do país de origem; de privacidade e de inviolabilidade de correspondência, dentre outros.

O Acordo sobre residência para nacionais dos Estados partes do Mercosul, Bolívia e Chile (2009) define:

Direito de exercer qualquer atividade, por conta própria ou por conta de terceiros, nas mesmas condições que os nacionais do país de recepção, particularmente o direito a trabalhar e exercer toda atividade lícita nas condições que dispõem as leis; peticionar às autoridades; ingressar, permanecer, transitar e sair do território das Partes; associarse com fins lícitos e professar livremente sua religião, em conformidade com as leis que regulamentem seu exercício;

- Direito à reunificação familiar: os membros da família que não possuam a nacionalidade de um dos Estados Partes, poderão solicitar uma residência de idêntica vigência daquela que possua a pessoa da 
qual dependam, desde que apresentem a documentação que se estabelece como requisito para a comprovação da relação familiar e não possuam impedimentos;

- Direito à igualdade de tratamento: os imigrantes gozarão, no território das Partes, de um tratamento não menos favorável daquele que recebem os nacionais do país de recepção, no que se refere à aplicação da legislação trabalhista, especialmente em matéria de remunerações, condições de trabalho e seguros sociais;

-Direito a transferir remessas: direito a transferir livremente ao seu país de origem sua renda e economias pessoais, particularmente os fundos necessários para o sustento dos seus familiares, em conformidade com a normativa e a legislação interna de cada uma das Partes;

Direitos dos filhos dos migrantes: os filhos dos imigrantes que tenham nascido no território de uma das Partes terão direito a ter um nome, um registro de nascimento e uma nacionalidade, em conformidade com as respectivas legislações internas. Os filhos dos imigrantes gozarão, no território das Partes, do direito fundamental de acesso à educação em condição de igualdade com os nacionais do país de recepção. $\mathrm{O}$ acesso às instituições de ensino pré-escolar ou às escolas públicas não poderá ser negado ou limitado devido à circunstancial situação irregular da estada dos pais. ${ }^{22}$

No Brasil, encontra-se em tramitação no Congresso Nacional o PL 5655/09 que altera a Lei 6.815/80 - Estatuto do Estrangeiro ${ }^{23}$. A Convenção da ONU acima referida não foi assinada ou ratificada pelo Brasil. O Conselho Nacional de Imigração, pela resolução n. 10/2008, recomenda a adesão.

Não obstante, sem pretensão de alimentar aqui o mito da democracia étnicoracial, é possível afirmar que, no caso do Brasil, ao contrário da imagem da justaposição de comunidades ou colônias - a nossa formação deve-se à contribuição de imigrantes de várias nacionalidades -, prevaleceria a imagem da "integração" e da miscigenação.

\section{Segundo a Constituição Federal (1988)}

Art. $4^{\circ}$ A República Federativa do Brasil rege-se nas suas relações internacionais pelos seguintes princípios:

$$
\begin{aligned}
& \text { I - independência nacional } \\
& \text { II - prevalência dos direitos humanos } \\
& \text { III - autodeterminação dos povos } \\
& \text { IV - não-intervenção } \\
& \text { V - igualdade entre os Estados } \\
& \text { VI - defesa da paz } \\
& \text { VII - solução pacífica dos conflitos }
\end{aligned}
$$

\footnotetext{
22 Como Trabalhar nos Países do MERCOSUL: Guia Dirigido aos Nacionais dos Estados partes do MERCOSUL / Ministério do Trabalho e Emprego (MTE) - Brasília: MTE, 2010. Disponível em: http:// portal.mte.gov.br/data/files. Acesso em 19/11/12.

${ }^{23}$ Cf. Ficha de Tramitação. Disponível em: http://www.camara.gov.br/proposicoes. Acesso em 19/11/12. Serv. Soc. \& Saúde, Campinas, SP v. 13, n. 2 (18) p. 261-282 jul./dez. 2014 ISSN 1676-6806
} 


\section{VIII - repúdio ao terrorismo e ao racismo \\ IX - cooperação entre os povos para o progresso da humanidade $\mathrm{X}$ - concessão de asilo político}

Mas, a entrada de haitianos no Brasil pela fronteira com o Peru e a Colômbia, reabre a polêmica quanto à política de imigração. De um lado, as preocupações humanitárias. De outro, as restrições e a imigração seletiva em nome da soberania nacional. $^{24}$

O Haiti ${ }^{25}$, país mais pobre das Américas, constitui flagrante exemplo do caráter neocolonialista da "ajuda humanitária" internacional ${ }^{26}$. Após o terremoto de 2010, os haitianos em luta pela sobrevivência, passaram a vir ao Brasil com a esperança de inserção em um mercado de trabalho "promissor" pelos investimentos em obras da construção civil em preparação para a Copa do Mundo e os Jogos Olímpicos (TALENTO, MOLINERO \& SOUZA, 14/1/12). E são vítimas de quadrilhas e de coiotes atravessadores em esquemas para entrada ilegal no país (HENNEMAN; SILVA, 26/12/11).

Bolivianos são protagonistas da cena urbana brasileira, vivendo em bairros paulistanos centrais como o Bom Retiro e em bairros periféricos como a Brasilândia. Os imigrantes bolivianos enfrentam, no Brasil, precárias condições de trabalho e renda, “análogas à escravidão" (TRINDADE, 05/08/12) em alguns casos que já foram objeto de intervenção do Ministério Público do Trabalho.

$\mathrm{Na}$ Colômbia registra-se o fenômeno dos deslocados internos ${ }^{27}$. Estima-se em três milhões o número de colombianos que deixaram zonas rurais disputadas - por diferentes motivos e interesses - por guerrilheiros, organizações paramilitares e traficantes de drogas. Mas, recentemente, o governo colombiano, por uma lei de restituição fundiária, lançou um programa nacional para devolver terras a agricultores deslocados (NEUMAN, 10/12/12).

\footnotetext{
${ }^{24}$ Ver, a propósito: ARAGÃO, M. (2012) e THOMAZ \& NASCIMENTO (2012).

${ }^{25}$ O país, de 28 mil km2, tem 9,7 milhões de habitantes, PIB de US\$ 6, 6 bilhões, analfabetismo de $47 \%$. Em fevereiro de 2001 cai o presidente Jean Bertrand Aristide e a ONU cria missão de Paz, sob comando do Brasil. Em janeiro de 2010 terremoto devasta Porto Príncipe. Em outubro de 2010 epidemia de cólera deixa 7000 mortos. Em outubro de 2011, a ONU define redução de tropas no Haiti. (MARREIRO: $02 / 02 / 12$ ). O terremoto afetou 3,5 milhões de pessoas, deixando 222.570 mortos, 300.572 feridos e 2,3 milhões desabrigados. $80 \%$ das pessoas vivem em situação de pobreza. Óbices políticos emperram a reconstrução (ROBERTSON, 12/01/12).

26 "Os bilhões entregues à cooperação ou às Nações Unidas se perdem na manutenção do aparato internacional no país e em insondáveis corredores onde burocracia e corrupção se encontram". (THOMAZ \& NASCIMENTO, 21/1/12).

${ }^{27}$ MAISONNAVE, 27/01/08. No Sudão seriam 5.350 .000 e no Iraque, 2.200.000. A matéria tem como fonte de dados o ACNUR.

Serv. Soc. \& Saúde, Campinas, SP v. 13, n. 2 (18) p. 261-282 jul./dez. 2014 ISSN 1676-6806
} 
Estima-se em cerca de um bilhão o número de migrantes em todo o mundo, dos quais 740 milhões são migrantes internos. Os migrantes internacionais seriam 188 milhões, distribuídos pela África (10,2\%), América do Norte (26,6\%), América Latina e Caribe (4,0\%), Ásia (29,6\%), Europa $(26,4 \%)$ e Oceania $(3,2 \%)^{28}$.

No caso do Brasil "[...] a proporção de estrangeiros no país ainda é pequena. Segundo o último censo do IBGE, eles representam cerca de $0,3 \%$ da população do Brasil. A média mundial é de 3\%, de acordo com a ONU, ou 214 milhões de pessoas vivendo e trabalhando em países estrangeiros" (ROLLI, 11/08/13).

As principais características da migração são: o alcance global, a quase metade dos migrantes constituída de mulheres, e a transnacionalização pela tecnologia da comunicação e a expectativa de controle pelos governos (DEPARLE, 2010).

Mas, vêm ocorrendo mudanças quanto à direção dos fluxos migratórios, destacando-se aqui a "migração intra-regional latino-americana". A reversão estaria no deslocamento de mexicanos no interior do próprio México, de guatemaltecos para o México, de bolivianos para a Argentina, de latino-americanos para o Chile, a Argentina e o Brasil (CAVE, 16/01/12).

O México seria um caso de reversão da imigração.

Hoje, mais de $75 \%$ dos imigrantes legais são americanos, mais que os dois terços de 2000. Nos últimos anos, mais americanos se somaram à população do México que mexicanos se radicaram nos Estados Unidos [...] Parte do crescimento imigrante acontece na região de fronteira, onde empresas estrangeiras e famílias binacionais já são comuns [...] A Europa, moribunda; o México, nascente. Os EUA, fechado e materialista: o México, aberto e criativo. São as percepções que movem a migração no mundo, e entrevistas feitas com recémchegados deixaram claro que a atratividade não se deve apenas ao fator econômico (CAVE, 01/10/13).

O êxodo reverso ou "dolorosa volta para casa" (DONADIO, TABUCHI e SCHWARTZ, 04/05/09) vem provocando a síndrome do regresso ${ }^{29}$ sofrida por brasileiros que retornam ao país ${ }^{30}$.

Ocorre que

[...] a crise dos países desenvolvidos está levando muitos brasileiros a fazerem as malas de volta para casa. Segundo o Itamaraty, $20 \%$ dos que moravam nos EUA e um quarto dos

\footnotetext{
${ }^{28}$ Cf. Relatório Ultrapassar Barreiras: Mobilidade e Desenvolvimento Humano. PNUD, ONU, 2009.

${ }^{29}$ Termo cunhado pelo neuropsiquiatra Décio Nakagawa, segundo Lourenço e Cunha, 06/03/12.

${ }^{30}$ Diante do intenso movimento de regresso por causa da crise de brasileiros emigrados, o governo federal vai lançar na Internet um portal com informações para facilitar a readaptação e a reinserção no mercado de trabalho (FOREQUE, 18/12/12).

Serv. Soc. \& Saúde, Campinas, SP v. 13, n. 2 (18) p. 261-282 jul./dez. 2014 ISSN 1676-6806
} 
que moravam no Japão já retornaram desde o começo da recessão, em 2008 (LOURENÇO, CUNHA, 06/03/12).

Ora, na condição de trabalhador em luta pela sobrevivência ou em busca de melhores condições de vida, o imigrante subordina-se, em condições ainda mais inseguras e precárias que os demais trabalhadores, à lógica do capital na gestão da mão de obra, segundo os ciclos econômicos. Na expansão, os imigrantes são atraídos, sob contratos flexíveis - leia-se precários - de trabalho. Na recessão, os imigrantes são repelidos por força de outros contratos em torno da "identidade nacional", da "segurança" e da "ordem", em contexto de violação de convenções internacionais quanto aos direitos humanos. Trata-se da superpopulação relativa em âmbito internacional.

[...] os países de origem vão sofrer, pois a imigração é sabidamente um forte redutor de pobreza para as famílias do Terceiro Mundo. Nos países de destino, temo que se chegue ao ponto em que imigrantes, particularmente ilegais, se tornarão alvos da população doméstica, como se fossem responsáveis pela falta de empregos. Além disso, quando a prosperidade retornar, a economia dos países ricos sofrerá se demorarem a reconquistar os imigrantes necessários. Os trabalhadores mais flexíveis são os imigrantes, e sua mobilidade geográfica é extremamente importante para os mercados de trabalho". (PAPADEMETRIOU, 06/04/09, destaques meus)

Em face de tal tendência, o Relatório Ultrapassar Barreiras: Mobilidade e Desenvolvimento Humanos, do PNUD/ONU (2009), propõe as seguintes medidas: abertura dos canais de entrada existentes para mais trabalhadores, sobretudo os menos qualificados; assegurar os direitos humanos básicos aos migrantes, desde o acesso a serviços básicos como a educação e os serviços de assistência médica até o direito ao voto; reduzir as despesas de transação da migração; encontrar soluções em parceria que beneficiem tanto as comunidades de destino como os migrantes; facilitar a migração interna; incluir a migração como uma componente das estratégias de desenvolvimento dos países de origem ${ }^{31}$.

Justifica-se a ênfase nos trabalhadores menos qualificados e no direito ao acesso a serviços sociais básicos, especialmente em contexto de crise e de precarização das condições de trabalho. Não se pode pretender uma posição de indiferença ou de resignação perante a condição dos trabalhadores imigrantes em várias partes do mundo.

\footnotetext{
${ }^{31} \mathrm{Cf}$. Mundo tem quase um bilhão de migrantes. Disponível em: http://www.pnud.org.br/. Acesso em $18 / 11 / 12$.

Serv. Soc. \& Saúde, Campinas, SP v. 13, n. 2 (18) p. 261-282 jul./dez. 2014 ISSN 1676-6806
} 
O presente estudo permitiu, em suma, identificar nas pautas de governos e de movimentos sociais e partidos ultraconservadores, variadas expressões de xenofobia, hostilidade e intolerância em face dos imigrantes em vários países, evidenciando a contradição entre a desregulação e livre circulação de capitais e mercadorias e, por outro lado, as crescentes restrições ao deslocamento de pessoas.

Nas atitudes de rejeição aos imigrantes foi possível entrever as armadilhas ideológicas da conversão do diferente em inimigo - recobrindo interesses econômicos na exploração de mão de obra - sob o pretexto de incompatibilidades étnico-culturais supostamente ameaçadoras de "integridades nacionais".

A concorrência entre trabalhadores nacionais e trabalhadores imigrantes - que serve aos interesses de redução dos custos da mão de obra - transmuta-se em questões de preservação da ordem, da segurança e da identidade cultural.

É preciso, pois, denunciar a tendência de suprimir regulações e fronteiras para o capital e para as mercadorias em favor da apropriação privada de riqueza no mercado globalizado e de, por outro lado, lançar milhões de pessoas à miséria e ao abandono, despojadas das condições mínimas para a participação na vida social, cultural, política e econômica, com acesso igualitário aos bens materiais e imateriais socialmente produzidos.

Diferenças étnico-culturais entre nacionais e imigrantes no interior de cada país $^{32}$ e entre países devem ser consideradas, uma vez que ensejam conflitos em várias partes do mundo. Não podem obscurecer, no entanto, antagonismos fundamentais entre detentores do capital e trabalhadores na condição de imigrantes em luta por acesso à riqueza social.

O projeto de uma sociedade igualitária à luz de critérios universalistas de justiça social, na construção de uma cultura de paz, demanda dos governantes, dos public policy makers, dos intelectuais na condição de dirigentes e da sociedade em geral - por meio de processos democráticos - a defesa da dignidade, da qualidade de vida, da segurança e do bem-estar dos trabalhadores imigrantes.

\footnotetext{
32 A Rússia abriga mais de 180 etnias, sendo que as mais representativas são: os cristãos étnicos (77,7\%), tártaros $(3,72 \%)$, ucranianos $(1,35 \%)$, bashkires $(1,11 \%)$ e tchetchenos (1\%). Reagindo aos conflitos étnicos, o governo russo vai implantar um plano de ação com 82 medidas, dentre as quais a inclusão da disciplina Cultura das Relações Inter-étnicas nos currículos escolares e universitários (Obrazkova, 21/8/13).

Serv. Soc. \& Saúde, Campinas, SP v. 13, n. 2 (18) p. 261-282 jul./dez. 2014 ISSN 1676-6806
} 


\section{Referências bibliográficas}

ACORDO Mercosul sobre residência para nacionais dos Estados partes do Mercosul, Bolívia e Chile. 2009

ARAGÃO, M. Imigração com regras e controles. THOMAZ, O. R.; NASCIMENTO, S. Europeus bem-vindos, haitianos barrados. In: O país deve limitar a entrada de imigrantes haitianos? Folha de São Paulo, 21/01/2012.

BERNICE, R. Haiti. 2 anos depois do (quase) fim. Folha de São Paulo, 12/01/2012.

BRITO, M. A. Dos indesejáveis errantes. In: Caros Amigos, n. 138, setembro de 2008.

CALIGARIS, C. Desgosto. Folha de São Paulo, 17/07/2008.

CALIGARIS, C. O risco de se perder. Folha de São Paulo, 24/07/2008.

CAPRIGLIONE, L. Terra sem lei. Folha de São Paulo, 01/02/2012.

CAPRIGLIONE, L. Brasileiro faz fortuna e má fama no Paraguai. Folha de São Paulo, 05/02/2012.

CARDOSO, C. França intensifica expulsão de ciganos. Folha de São Paulo, 20/08/2010.

CARNEIRO, M. Portugal oferece visto em troca de investimento. Folha de São Paulo. Mercado, 28/09/2012.

CAVE, D. Novas rotas de imigração nas Américas. O norte não é mais o único caminho de oportunidades. The New York Times. Encarte da Folha de São Paulo, 16/1/2012.

CAVE, D. México reverte imigração. The New York Times, Encarte da Folha de São Paulo, 01/10/13.

COELHO, L. Premiê britânico fecha cerco à imigração. Folha de São Paulo, 13/11/2009.

COMO Trabalhar nos Países do MERCOSUL: Guia Dirigido Nacionais dos Estados partes do MERCOSUL / Ministério do Trabalho e Emprego (MTE) ... [ et al.]. Brasília: MTE, 2010. Disponível em: http://portal.mte.gov.br/data/files. Acesso em 19/11/2012.

Convenção das Nações Unidas para a proteção de todos os trabalhadores migrantes e membros de suas famílias. 1990.

CRESCE presença de engenheiro português no país. Folha de São Paulo, 28/9/2012.

CROSSlAnd, D. Xenofobia at the heart of German Politics. Disponível em: www.spiegel.de/international/germany Acesso em: 05/04/2012. 
CUBA admite o retorno de cidadãos que fugiram. Folha de São Paulo. Caderno Mundo. 26/10/2012

DEMPSEY, J. Alemanha busca trabalhadores. The New York Times. Encarte Folha de São Paulo, 21/02/2011.

DEPARLE, J. Um mundo em movimento. The New York Times. Encarte Folha de São Paulo, 05/07/2010.

DEPARLE, J. Migração desafia economia fraca. The New York Times. Encarte Folha de São Paulo, 7/6/2010.

DIAS, R.; KANNO, M.; BAPTISTA, V. A.; PULS, M.; SEVERINO, T.; DUCROQueT, S.; Pliger, M.; CAVAlEIRO, C. Mundo Árabe. Folha de São Paulo, 03/03/2011.

DICIONÁRIO Houaiss da Língua Portuguesa. Rio de Janeiro, $1^{\text {a }}$ ed., 2001.

DONADIO, R.; TABUCHI, H.; SCHWARTZ, N. A dolorosa volta para casa. The New York Times. Encarte Folha de São Paulo, 4/5/2009.

EM MEIO à crise, Europa fecha cerco a fluxo de imigrantes. Folha de São Paulo, $12 / 5 / 2011$.

ÉTRANGERS en Suisse. Disponível em: http://www.jsvp.ch/francais/positions.htm. Acesso em 16/11/12.

FIBE, C. Obama faz apelo por reforma migratória. Folha de São Paulo, 2/7/2012.

FINLÂNDIA enfrenta subida do populismo. Disponível em: www.euronews. 06/05/2011. Acesso em 19/11/2012.

FOREQUE, F. Repatriado terá site com "caminho das pedras". Folha de São Paulo, $18 / 11 / 2012$.

GRÉCIA: ONGs dizem que imigrantes são “bodes expiatórios” para a crise. Disponível em: www.euronews. 20/10/12. Acesso em 19/11/2012.

HENNEMAN, G.; SILVA, J. Haitianos desembolsam US\$ 300 para entrar ilegalmente no Brasil. Folha de São Paulo, 26/12/2011.

IMACHE, T. Estrangeiros para nós mesmos. Le Monde Diplomatique, n. 16, novembro de 2008 .

Imigrantes desenhados como vassouras choca Rússia. Disponível em: www.euronews. 24/10/12. Acesso em 19/11/2012.

Itália endurece ação contra ilegais. Folha de São Paulo, 24/7/2008. 
JOHNSON, I. Chineses emigram em busca de oportunidades. Folha de São Paulo/New York Times, 12/11/2012

KULISH, N. Ataques a ciganos crescem em meio à turbulência econômica. Folha de São Paulo/New York Times, 04/05/2009.

Língua portuguesa. Folha de São Paulo, 3/3/2012.

Londres limita número de imigrantes. Folha de São Paulo, 29/6/2010.

LOURENÇO, A.; CUNHA, J. Síndrome da volta pra casa. Folha de São Paulo. Equilíbrio, 06/03/2012.

MAISONNAVE, F. Mais de 3 milhões estão deslocados dentro da Colômbia. Folha de São Paulo, 27/001/2008.

MARINHEIRO, V. UE ameaça punir França por xenofobia. Folha de São Paulo, 15 de setembro de 2010 .

MARINHEIRO, V. Banir véu é antibritânico, diz ministro. Folha de São Paulo, 25/07/2010.

MARINHEIRO, V. Itália não sabe o que fazer com tunisianos. Folha de São Paulo, 18/02/2011.

MARINHEIRO, V. Barco com imigrantes amedronta ilha. Folha de São Paulo, 19/02/2011.

MARINHEIRO, V. Em ilha, jovens batem à porta da Europa. Folha de São Paulo, 20/02/2011.

MARREIRO, F. No Haiti, Dilma promete combater 'coiotes'. Folha de São Paulo, 02/02/2012.

MARINHEIRO, V. Regime promete liberar viagens de cubanos. Folha de São Paulo, $14 / 4 / 12$

MARTIN, M. Estrangeiros tentam visto com 'casamento de aluguel'. Folha de S. Paulo, 08/07/12.

MATTEWMAN, J. Os novos nômades globais. São Paulo: Clio Editora, 2012.

MIGRANTES ajudam mais que países ricos. Folha de São Paulo, 05/10/2009

MUNDO tem quase um bilhão de migrantes. Disponível em: http://www.pnud.org.br/. Acesso em 18/11/2012.

MURTA, A. Republicanos miram "turismo de parto". Folha de São Paulo, 12/8/2010.

NAIM, M. Abismo fiscal: símbolo do declínio? Folha de São Paulo, 7/12/2012. 
NEUMAN, W. Governo colombiano lança programa de devolução de terras. New York Times. Encarte Folha de S. Paulo, 10/12/2012.

NETO, P. C. É presente de grego. Folha de São Paulo, 15/03/2012.

ONU. Declaração Universal dos Direitos Humanos. 1948.

Osce: D’Amico, contrari a Europa multietnica. Disponível em: www.leganord.org/index.php/notizie. Acesso em: 18/11/2012.

Os ciganos na Europa. Folha de São Paulo, 20/08/2010 apud LIÉGEOIS, Jean-Pierre, 2007.

PAPADEMETRIOU, D. Em entrevista a Andrea Murta. Crise econômica ameaça era histórica de mobilidade. Folha de São Paulo, 06/04/2009.

PIOT, O. Os sem-papéis também lutam. Le Monde Diplomatique, junho de 2008.

POLÍTICA Nacional de Imigração e Proteção ao Trabalhador Migrante. Brasília: MTE/Conselho Nacional de Imigração, 2010.

RELATÓRIO Ultrapassar Barreiras: Mobilidade e Desenvolvimento Humano. PNUD/ONU, 2009.

ROBERTSON, B. Haiti. 2 anos depois do (quase) fim. Folha de São Paulo, $12 / 01 / 2012$.

ROLLI, C. Aumenta o registro de trabalhadores imigrantes em SP. Folha de São Paulo, 11/08/2013.

ROTH, A. Jovens russos lideram ataques a imigrantes. The New York Times. Encarte da Folha de São Paulo, 24/09/2013.

SAFATLE, V. O fim da tolerância. Folha de São Paulo, 01/3/2011.

SANG-HUN, C. Imigração mudou identidade sul-coreana. New York Times. Encarte da Folha de São Paulo, 17/12/2012.

SEITENFUS, R.; VENTURA, D. Triste Europa. Folha de São Paulo, 24/7/2008.

SCHWARTSMAN, H. Iniciativa da oposição tem poucas chances de dar certo. Folha de São Paulo, 12/8/2010.

SCHWARTSMAN, H. Censurando o dicionário. Folha de São Paulo, 2/3/2012.

TALENTO, A.; MOLINERO, B.; SOUZA, M. L. O Haiti quer ser aqui. Folha de São Paulo, 14/1/2012.

THOMAZ, O. R.; NASCIMENTO, S. Europeus bem-vindos, haitianos barrados. In: O país deve limitar a entrada de imigrantes haitianos? Folha de São Paulo, 21/1/2012. 
VILA-NOVA, C. Na contramão, Canadá busca imigrantes. Folha de São Paulo, 26/12/2007.

Xenofobia na França. Editorial da Folha de São Paulo, 12/9/2010.

\section{Brasil: Leis e Decretos}

Constituição Federal, 1988.

Lei 6.815/80 - Estatuto do Estrangeiro

Decreto n. 6975/09 - Acordo de Residência para Nacionais dos Estados Partes do Mercosul, Bolívia e Chile.

Projeto de Lei n. 5655/09 - Alteração do Estatuto do Estrangeiro. 